\title{
Exercise ameliorates the FGF21-adiponectin axis impairment in diet-induced obese mice
}

\author{
Wenqi Yang ${ }^{1,2, *}$, Ling Liu',*, Yuan Wei ${ }^{1,2}$, Chunlu Fang ${ }^{1,2}$, Fu Zhou ${ }^{2}$, Jinbao Chen², Qinghua Han², Meifang Huang ${ }^{2}$, \\ Xuan Tan'2, Qiuyue Liu², Qiang Pan², Lu Zhang ${ }^{2}$, Xiaojuan Lei ${ }^{2}$ and Liangming Li ${ }^{1,2}$ \\ ${ }^{1}$ Center for Scientific Research and Institute of Exercise and Health, Guangzhou Sports University, Guangzhou, China \\ ${ }^{2}$ Key Laboratory of Sports Technique, Tactics and Physical Function of General Administration of Sport of China, Scientific Research Center, Guangzhou \\ Sport University, Guangzhou, China
}

Correspondence should be addressed to L Li: liangming12j@126.com

*(W Yang and L Liu contributed equally to this work)

\begin{abstract}
Objective: The protective effects of exercise against glucose dysmetabolism have been generally reported. However, the mechanism by which exercise improves glucose homeostasis remains poorly understood. The FGF21-adiponectin axis participates in the regulation of glucose metabolism. Elevated levels of FGF21 and decreased levels of adiponectin in obesity indicate FGF21-adiponectin axis dysfunction. Hence, we investigated whether exercise could improve the FGF21-adiponectin axis impairment and ameliorate disturbed glucose metabolism in diet-induced obese mice.

Methods: Eight-week-old C57BL/6J mice were randomly assigned to three groups: low-fat diet control group, high-fat diet group and high-fat diet plus exercise group. Glucose metabolic parameters, the ability of FGF21 to induce adiponectin, FGF21 receptors and co-receptor levels and adipose tissue inflammation were evaluated after 12 weeks of intervention. Results: Exercise training led to reduced levels of fasting blood glucose and insulin, improved glucose tolerance and better insulin sensitivity in high-fat diet-induced obese mice. Although serum FGF21 levels were not significantly changed, both total and highmolecular-weight adiponectin concentrations were markedly enhanced by exercise. Importantly, exercise protected against high-fat diet-induced impaired ability of FGF21 to stimulate adiponectin secretion. FGF21 co-receptor, $\beta$-klotho, as well as receptors, FGFR1 and FGFR2, were upregulated by exercise. We also found that exercise inhibited adipose tissue inflammation, which may contribute to the improvement in the FGF21-adiponectin axis impairment.

Conclusions: Our data indicate exercise protects against high-fat diet-induced FGF21-adiponectin axis impairment, and may thereby exert beneficial effects on glucose metabolism.
\end{abstract}

Endocrine Connections (2019) 8, 596-604

\section{Introduction}

The prevalence of diabetes is growing rapidly around the world. An estimated 415 million people aged 20-79 years suffered from diabetes in 2015 and it is predicted that the number of people with diabetes aged 20-79 years will rise to 642 million by 2040 (1). Type 2 diabetes mellitus (T2DM) accounts for approximately $90 \%$ of all diabetes cases (2). Promising targets to improve glucose homeostasis are of particular interest.

Fibroblast growth factor 21 (FGF21), a member of the fibroblast growth factor superfamily, has attracted increasing attention in recent years for its role in regulating glucose and lipid metabolism.
This work is licensed under a Creative Commons Attribution-NonCommercial 4.0 International License. ded from Bioscientifica.com at 04/26/2023 07:21:16AM 
During the consumption of a ketogenic diet or a high-fat diet, FGF21-knockout mice develop more insulin resistance and show more disorganized liver lipid metabolism compared to their WT littermate controls $(3,4,5)$. On the other hand, replenishment of FGF21 can reduce obesity, improve insulin sensitivity and increase glucose clearance $(5,6)$. FGF21 exerts its biological actions through binding to FGF receptors (FGFRs) and an essential co-receptor, $\beta$-klotho (7), forming the FGF21 receptor complex.

FGF21 is produced predominantly in the liver $(4,8)$. Adipose tissue is a primary target of FGF21 action. Adipose tissue-specific FGFR1 or $\beta$-klotho knockout abolishes FGF21 effects on glucose and energy regulation $(9,10)$. Adiponectin, an insulin-sensitizing adipokine, has been shown as an effector of FGF21. Both acute and chronic FGF21 treatment increase the secretion and expression of adiponectin partly through PPAR $\gamma$ (11). FGF21 significantly reverses the tumor necrosis factor $\alpha$ (TNF $\alpha$ )-induced impairment in adiponectin secretion (12). Furthermore, adiponectin deficiency abrogates the benefits of FGF21 on glucose and lipid control (11). A growing body of studies provide convincing evidence demonstrating that the FGF21-adiponectin axis plays an important role in regulating glucose homeostasis through the crosstalk between the liver and adipose tissue $(11,12,13)$.

The beneficial effects of exercise on glucose homeostasis are well documented (14), and exercise has been shown to reduce adipogenesis, alleviate adipose tissue inflammation and improve the disturbed pattern of adipokine secretion $(15,16)$. Studies have shown that exercise affects serum levels of FGF21 and increases circulating adiponectin concentrations $(16,17,18)$. However, no one has addressed the question whether exercise had an impact on the FGF21adiponectin axis. Given that the FGF21-adiponectin axis exerts protective effects on glucose homeostasis, we speculated the FGF21-adiponectin axis may play a crucial role in exercise-related benefits on glucose metabolism. The aim of our present study was to investigate whether exercise could alleviate the FGF21-adiponectin axis impairment and ameliorate glucose metabolism and insulin resistance in diet-induced obese mice.

\section{Materials and methods}

\section{Animals and diet}

Eight-week-old male C57BL/6J mice were randomly divided into a low-fat diet control group (LFD, $n=24$ ), a high-fat diet group (HFD, $n=24$ ) and a high-fat diet plus exercise group $(\mathrm{HFD}+\mathrm{EXE}, n=24)$. The mice from LFD group received a low-fat diet containing 10\% kcal from fat (D12450J, Research Diets Inc.). Both the HFD mice and the HFD+EXE mice were fed a high-fat diet containing 60\% kcal from fat (D12492, Research Diets Inc.) for 12 weeks. At the same time, mice in HFD+EXE group were subjected to exercise training. All animals were kept under $12 \mathrm{~h}$ light-darkness cycles at $22-24^{\circ} \mathrm{C}$, with free access to food and water. Body weight was recorded weekly. Two days after the final training session, mice were subjected to FGF21-induced adiponectin examination or killed for collection of serum, liver and adipose tissue under anesthesia (sodium pentobarbital $50 \mu \mathrm{g} / \mathrm{g}$ ). All procedures were approved by the Institutional Animal Care and Use Committee of Guangzhou Sport University (2018DWLL-003).

\section{Exercise protocol}

The HFD + EXE mice were trained on a treadmill at $0 \%$ grade 5 days per week for 12 weeks. Five minutes of warm up at $6 \mathrm{~m} / \mathrm{min}, 20 \mathrm{~min}$ of main exercise at $10 \mathrm{~m} / \mathrm{min}$, and $5 \mathrm{~min}$ of cool down at $6 \mathrm{~m} / \mathrm{min}$ were performed during the first week for adaptation. From the 2 nd week to the 12 th week, $5 \mathrm{~min}$ of warm up at $6 \mathrm{~m} / \mathrm{min}, 50 \mathrm{~min}$ of main exercise at $12 \mathrm{~m} / \mathrm{min}$ (75\% maximum oxygen consumption) (19), and $5 \mathrm{~min}$ of cool down at $6 \mathrm{~m} / \mathrm{min}$ were performed.

\section{Blood analysis}

Triglyceride (TG), total cholesterol (TC), low-density lipoprotein-cholesterol (LDL-C) and high-density lipoprotein-cholesterol (HDL-C) were measured in serum by commercial kits (BioSino Biotechnology Company, Ltd., Beijing, China). Serum insulin (Alpco Diagnostics, Salem, NH, USA), total and high-molecular-weight (HMW) adiponectin (Alpco Diagnostics) and FGF21 (R\&D Systems) were determined using commercial ELISA kit according to the manufacturer's instructions.

\section{FGF21-induced adiponectin examination}

To analyze the effects of acute FGF21 intervention on adiponectin secretion, the mice were intraperitoneally administered saline or $2 \mu \mathrm{g} / \mathrm{g}$ (11) of recombinant human FGF21 (PeproTech Inc., Rocky Hill, NJ, USA). After a 2-h fast, mice were killed. Serum was collected for total and HMW adiponectin determination.

\section{Oral glucose tolerance test (OGTT)}

OGTT was performed after 10 weeks of diet and exercise intervention. Following overnight fasting, mice were

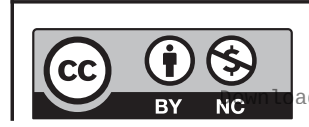

This work is licensed under a Creative Commons Attribution-NonCommercial 4.0 International License. ded from Bioscientifica.com at 04/26/2023 07:21:16AM 
given a glucose load $(1 \mathrm{mg} / \mathrm{g})$ orally. Blood sample was collected from the tail vein at various time points $(0,15$, $30,60,90,120 \mathrm{~min}$ ) for glucose determination using the Accu-Chek Performa glucometer (Roche).

\section{Insulin tolerance test (ITT)}

ITT was performed after 10 weeks of diet and exercise intervention. After a 3-h fast, mice received an intraperitoneal injection of diluted human insulin (Actrapid, Novo Nordisk) at a dose of $0.75 \mathrm{IU} / \mathrm{kg}$. Tail vein blood glucose was measured with a glucometer at $0,15,30,60,90,120$ min after injection.

\section{Homeostatic model assessment for insulin resistance (HOMA-IR) calculation}

HOMA-IR was calculated to assess the insulin resistance, using the formula: HOMA-IR=fasting glucose $(\mathrm{mmol} / \mathrm{L}) \times$ fasting insulin $(\mathrm{mIU} / \mathrm{L}) / 22.5(20)$.

\section{Quantitative real-time PCR}

Total RNA was extracted from epididymal white adipose tissue (WAT) and liver with TRIzol Reagent (Invitrogen). Quantitative PCR was carried out on the Applied Biosystems 7000 sequence detectionsystem with the primers shown in Supplementary Table 1 (see section on supplementary data given at the end of this article). Calculations were done using a comparative method $\left(2^{-\Delta \Delta C t}\right)$ and normalized to $\beta$-actin as housekeeping genes.

\section{Immunohistochemistry analysis}

For F4/80 staining, epididymal WAT samples were fixed in 4\% paraformaldehyde solution for $24 \mathrm{~h}$, embedded in paraffin. After deparaffinized and rehydrated, the WAT sections were stained with F4/80 antibody (Santa Cruz Biotechnology), and then revealed by DAB (Vector Laboratories).

\section{Statistical analysis}

All data were expressed as mean \pm s.E.M. values. Statistical significance between two groups was evaluated by twotailed Student's $t$-test, and for more than two groups by one-way ANOVA. All analyses were performed using SPSS 20.0. Differences with a $P$ value less than 0.05 were considered to be significant.

\section{Results}

\section{Exercise reduces HFD-induced adiposity} and hyperlipidemia

Compared with mice in the LFD group, HFD-fed mice became obese, indicated by greater weight gain as well as significant increase in epididymal and subcutaneous fat weight. Twelve weeks of exercise training showed remarkable improvement in obesity caused by HFD. The body weight and adipose tissue fat weight in the HFD+EXE group were significantly lower than those in the HFD group. Serum TG, TC and LDL-C levels were significantly increased in HFD mice. Exercise ameliorated HFD-induced hyperlipemia (Table 1).

\section{Exercise protects against deranged glucose homeostasis under a HFD challenge}

Fasting blood glucose and insulin levels were significantly increased in HFD-fed mice. Exercise training protected

Table 1 Metabolic parameters of male C57BL/6J mice received a low-fat diet (LFD), a high-fat diet (HFD) or a high-fat diet plus exercise training (HFD + EXE).

\begin{tabular}{l}
\hline Metabolic parameters \\
\hline Initial body weight $(\mathrm{g})$ \\
Final body weight $(\mathrm{g})$ \\
Body weight gain $(\mathrm{g})$ \\
Epididymal fat weight (g) \\
Epididymal fat/body weight ratio (\%) \\
Subcutaneous fat weight (g) \\
Subcutaneous fat/body weight ratio (\%) \\
Serum metabolites \\
TG (mmol/L) \\
TC (mmol/L) \\
LDL-C (mmol/L) \\
HDL-C (mmol/L)
\end{tabular}

\begin{tabular}{c}
\hline LFD \\
\hline $20.5 \pm 0.4$ \\
$26.0 \pm 0.8$ \\
$5.5 \pm 0.4$ \\
$0.27 \pm 0.03$ \\
$1.00 \pm 0.09$ \\
$0.24 \pm 0.04$ \\
$0.94 \pm 0.15$ \\
$0.36 \pm 0.03$ \\
$2.36 \pm 0.08$ \\
$0.17 \pm 0.02$ \\
$2.13 \pm 0.14$ \\
\hline
\end{tabular}

\begin{tabular}{c}
\hline HFD \\
\hline $20.1 \pm 0.4$ \\
$38.5 \pm 1.2^{\mathrm{a}}$ \\
$18.4 \pm 0.8^{\mathrm{a}}$ \\
$2.04 \pm 0.14^{\mathrm{a}}$ \\
$5.26 \pm 0.23^{\mathrm{a}}$ \\
$1.78 \pm 0.16^{\mathrm{a}}$ \\
$4.63 \pm 0.38^{\mathrm{a}}$ \\
$0.57 \pm 0.06^{\mathrm{a}}$ \\
$3.40 \pm 0.15^{\mathrm{a}}$ \\
$0.27 \pm 0.03^{\mathrm{a}}$ \\
$2.55 \pm 0.19$ \\
\hline
\end{tabular}

\begin{tabular}{c}
\hline LFD + EXE \\
\hline $20.3 \pm 0.4$ \\
$27.9 \pm 0.4^{\mathrm{b}}$ \\
$7.6 \pm 0.2^{\mathrm{a}, \mathrm{b}}$ \\
$0.55 \pm 0.04^{\mathrm{b}}$ \\
$1.94 \pm 0.11^{\mathrm{a}, \mathrm{b}}$ \\
$0.49 \pm 0.04^{\mathrm{b}}$ \\
$1.78 \pm 0.16^{\mathrm{b}}$ \\
$0.38 \pm 0.03^{\mathrm{b}}$ \\
$2.84 \pm 0.11^{\mathrm{a}, \mathrm{b}}$ \\
$0.19 \pm 0.01^{\mathrm{b}}$ \\
$2.29 \pm 0.17$
\end{tabular}

Data are mean \pm SEM. $n=10$ per group.

${ }^{a} P<0.05$ for difference from LFD; ${ }^{b} p<0.05$ for difference from HFD. 
against HFD-induced hyperglycemia and hyperinsulinemia (Fig. 1A and B). HOMA-IR indicating insulin resistance caused by HFD was ameliorated in HFD+EXE mice (Fig. 1C). The protective effects of exercise against insulin resistance were further confirmed by ITT. Compared with the HFD mice, the HFD+EXE mice showed reduced blood glucose excursion and area under the curve (AUC) analysis during ITT (Fig. 1D and E). Tolerance to the oral glucose challenge was also improved by exercise training (Fig. 1F and G).

\section{Exercise does not lead to a significant increase in circulating FGF21 concentrations but enhances adiponectin levels in HFD-fed mice}

To evaluate the effects of exercise on the FGF21-adiponectin axis, we set out to detect the levels of FGF21 and adiponectin. Compared with the LFD feeding, the HFD feeding resulted in a significant increase in FGF21 levels (Fig. 2A, B and C). Although FGF21 mRNA expression in WAT was slightly enhanced by exercise, no significant difference in serum levels and hepatic mRNA expression of FGF21 was observed between the HFD and HFD + EXE mice (Fig. 2A, B and C). Compared to LFD mice, HFD mice exhibited lower levels of adiponectin. Exercise enhanced both total and HMW adiponectin concentrations. Adiponectin mRNA expression in adipose tissue was also markedly elevated by exercise (Fig. 2D, E and F).
Exercise ameliorates HFD-induced impaired ability of FGF21 to stimulate adiponectin secretion

Administration of FGF21 led to a rapid and dramatic increase in both total and HMW adiponectin secretion. This response is impaired by HFD feeding (Fig. 3A, B, C and D). In LFD mice, FGF21 administration increased circulating levels of total and HMW adiponectin by 74 and $138 \%$, respectively. However, in HFD mice, FGF21 stimulation only enhanced total and HMW adiponectin by 36 and $83 \%$, respectively. We observed a $51 \%$ increase in total adiponectin concentrations and a $147 \%$ elevation in HMW adiponectin secretion upon FGF21 stimulation in HFD + EXE mice (Fig. 3B and D), indicating that exercise protects against HFD-induced reduction of FGF21mediated adiponectin secretion.

\section{Exercise increases $\beta$-klotho and FGFRs expression in WAT}

The biological function of FGF21 is mediated by its receptors and an essential co-receptor, $\beta$-klotho (7). We assessed $\beta$-klotho and FGFRs mRNA expression in WAT. HFD mice showed significantly lower mRNA expression of $\beta$-klotho, FGFR1, FGFR2 and FGFR3 than LFD mice (Fig. 4A, B, C and D). Compared with HFD mice, $\beta$-klotho mRNA levels were increased by 2.5 -fold in HFD + EXE mice and FGFR1, the most abundant receptor in WAT, was enhanced by $83 \%$ (Fig. $4 \mathrm{~A}$ and $\mathrm{B}$ ). Exercise also significantly increased FGFR2 mRNA expression in WAT
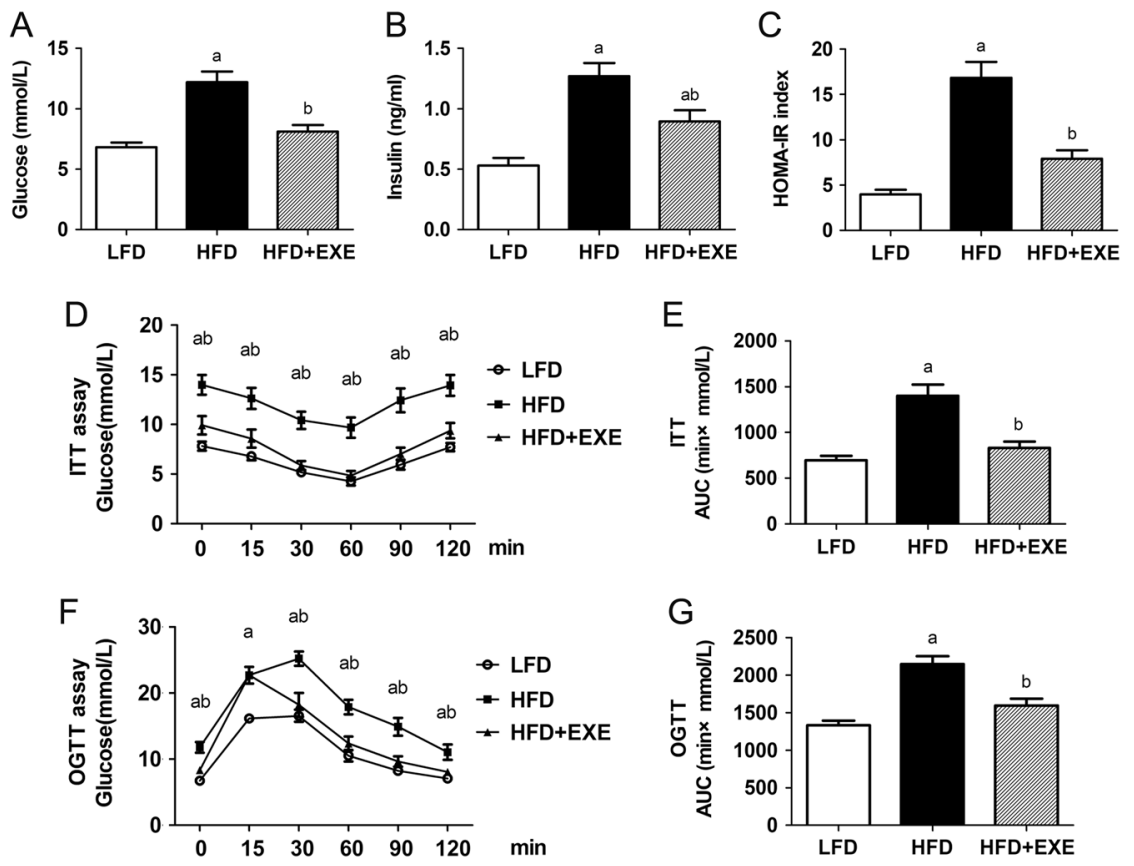

Figure 1

Exercise ameliorates glucose metabolism in HFD-induced obese mice. (A) Fasting blood glucose levels. (B) Basal insulin levels. (C) HOMA index of insulin resistance. (D) ITT was performed in LFD-fed, HFD-fed and HFD-fed plus exercise mice. (E) AUC analysis during ITT. (F) OGTT was performed in LFD-fed, HFD-fed and HFD-fed plus exercise mice. (G) AUC analysis during OGTT. Data are presented as the mean \pm S.E.M.; $n=10$ per group. ${ }^{a} P<0.05$ for difference from LFD; ${ }^{b} P<0.05$ for difference from HFD. https://ec.bioscientifica.com https://doi.org/10.1530/EC-19-0034 (c) 2019 The authors Published by Bioscientifica Ltd

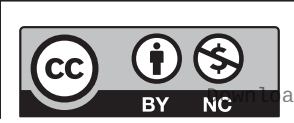

This work is licensed under a Creative Commons Attribution-NonCommercial 4.0 International License. ded from Bioscientifica.com at 04/26/2023 07:21:16AM via free access 
A

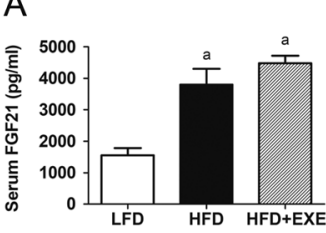

$\mathrm{D}$

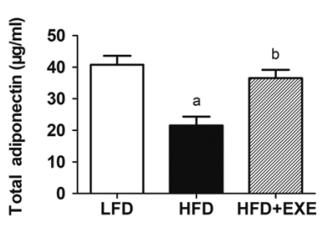

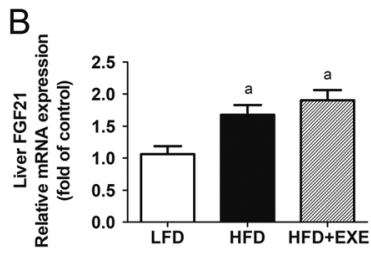

$\mathrm{E}$

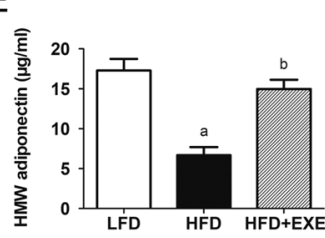

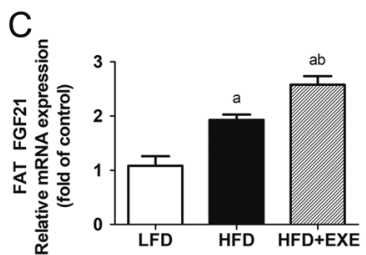

$\mathrm{F}$

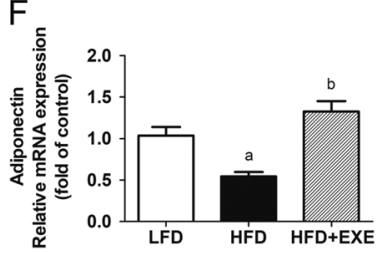

Figure 2

The effects of exercise on FGF21 and adiponectin levels was determined. (A) Serum levels of FGF21. (B) FGF21 mRNA expression in the liver. (C) mRNA expression of FGF21 in epididymal WAT. (D) Serum levels of total adiponectin. (E) HMW adiponectin concentrations in circulation. (F) Adiponectin mRNA levels in epididymal WAT. Data are presented as the mean \pm S.E.M.; $n=9-10$ per group. ${ }^{a} P<0.05$ for difference from LFD; ${ }^{b} p<0.05$ for difference from HFD.
(Fig. 4C). No difference was observed in the FGFR4 mRNA expression among the three groups (Fig. 4E).

\section{Exercise reduces HFD-induced inflammation in WAT}

Studies have suggested that inflammation contributes to the impairment of FGF21 action. $(21,22)$. We examined whether exercise alleviated inflammation in WAT. F4/80, an established marker of mature macrophages, was detected. Exercise reduced HFD-induced accumulation of adipose macrophages, suggested by decreased formation of crown-like structures (defined as F4/80-positive cells surrounding a degenerating adipocyte (23)) and a significant reduction in F4/80 mRNA levels (Fig. 5A and B). HFD feeding increased the expression of proinflammatory cytokines TNF $\alpha$, IL-1 $\beta$, IL-6 and MCP-1, which was largely prevented by exercise training (Fig. 5B).

\section{Discussion}

Multiple studies have demonstrated that exercise improves glucose metabolism effectively. Exercise training ameliorates blood glucose concentrations, glycated hemoglobin (HbA1c) levels, hyperinsulinemia, hyperlipemia, blood pressure and mortality in patients with T2DM $(24,25)$. Various mechanisms including stimulation of glucose uptake in skeletal muscle, enhancement of insulin sensitivity, reduction in hepatic gluconeogenesis and improvement of pancreatic beta-cell function are involved in exercise-elicited improvement of glucose homeostasis $(26,27)$. Our results also showed clearly that 12 weeks of exercise effectively protected against HFD-induced obesity, hyperglycemia, impaired glucose tolerance and insulin resistance. The mechanism underlying the benefits of exercise on glucose metabolism is still imperfectly understood. The present study demonstrated that instead of increase FGF21 levels, exercise sensitizes FGF21 action to induce adiponectin in adipose tissues. This interesting finding increases our understanding of how exercise exert its protective effects against glucose dysregulation.

FGF21, firstly identified in embryonic mouse embryo in 2000 (28), is expressed predominantly by the liver $(8,28)$. FGF21 exerts its biological function as an important metabolic regulator. Since FGF21-elicited glucose uptake on 3T3-L1 adipocytes was reported by Alexei Kharitonenkov in 2005 (6), the effects of FGF21 on glucose metabolism have been gradually revealed. FGF21 treatment significantly reduced blood glucose, enhanced insulin sensitivity and improved glucose clearance in obese animals $(6,29)$. Loss- and gain-of-function experiments
A
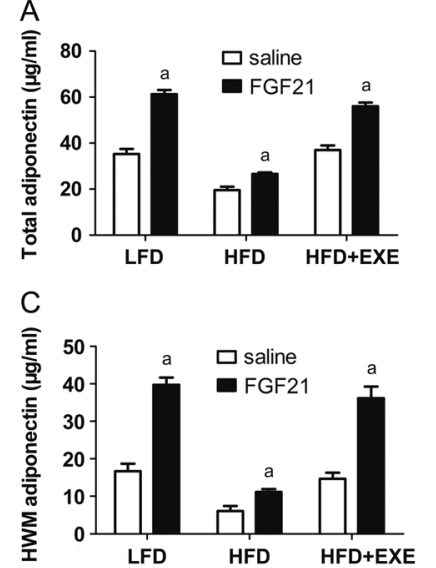

B

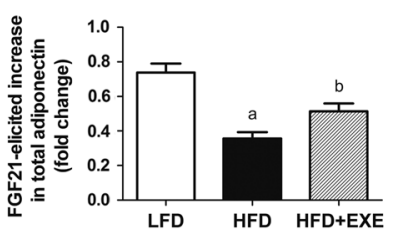

D

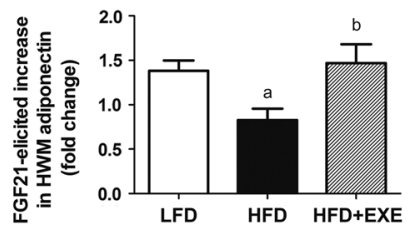

\section{Figure 3}

Exercise improves the ability of FGF21 to induce adiponectin secretion in HFD-induced obese mice. (A) FGF21 stimulates total adiponectin secretion. (B) Fold increase of FGF21-induced total adiponectin secretion. (C) FGF21 increases HMW adiponectin secretion. (D) Fold increase of FGF21-induced HMW adiponectin secretion. Data are presented as the mean \pm S.E.M.; $n=7$ per group. For $A$ and $C, a p<0.05$, saline administration vs FGF21 administration. For $B$ and $D,{ }^{a} P<0.05$ for difference from LFD; ${ }^{b} P<0.05$ for difference from HFD.
This work is licensed under a Creative Commons Attribution-NonCommercial 4.0 International License. ded from Bioscientifica.com at 04/26/2023 07:21:16AM 
A

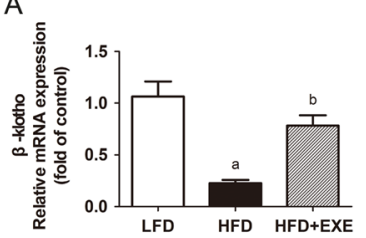

$D$

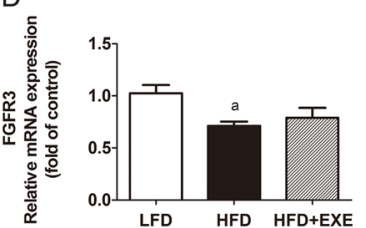

B

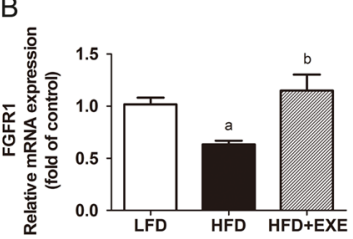

E

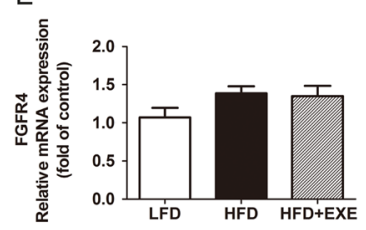

C

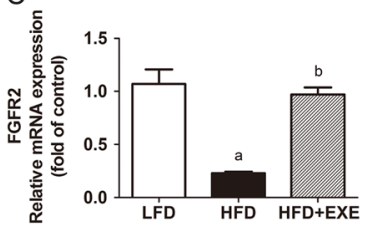

Figure 4

Exercise enhances $\beta$-klotho, FGFR1 and FGFR2 mRNA expression in epididymal WAT. (A) $\beta$-Klotho mRNA expression in WAT. (B, $C, D$ and $E$ ) FGFRs mRNA levels in WAT. Data are presented as the mean \pm S.E.M.; $n=9$ per group. ${ }^{a} P<0.05$ for difference from LFD; ${ }^{b} P<0.05$ for difference from HFD. further demonstrated that FGF21 played a crucial role in maintain glucose homeostasis $(6,30)$. FGF21 has been suggested as an exercise-induced hormone-like factor. Only a single bout of acute exercise increases circulating FGF21 $(17,31,32)$. The exercise-induced FGF21 response is regulated by enhanced glucagon-to-insulin ratio during exercise (32). However, long-term effects of exercise on FGF21 regulation remains inconclusive. FGF21 was decreased after 12 weeks of combined aerobic and resistance training in obese women (33), whereas no change was detected after a 8-week endurance training in obese men (34). In the present study, we did not observe any significant difference in the circulating levels of FGF21 between the HFD and HFD+EXE mice after 12 weeks of aerobic exercise. The role of exercise in FGF21 regulation may depend on exercise type, exercise mode, exercise intensity, intervention duration and even characteristics of trial subjects.

Adiponectin, a well-known adipokine, is produced almost exclusively by adipocytes (35) and exhibits anti-diabetic properties. Serum adiponectin levels are decreased in patient with obesity and T2DM, and in the general population, low circulating adiponectin levels are associated with increased risk of T2DM (36). Administration of adiponectin to diabetic animals corrected glucose disturbance (37). In blood, adiponectin exists as three main forms: HMW, middle molecular weight hexameric (MMW) and low-weight trimer (LMW) (38). The HMW adiponectin has been considered as the most biologically active isoform and improve insulin sensitivity and glucose uptake $(39,40)$. Our results showed that aerobic exercise increased adiponectin, especially HWM adiponectin in HFD-fed mice. This improvement may account for exercise-induced glucose metabolic benefit.

Although the major production site is different, there are many functional similarities between FGF21 and adiponectin. Researchers hypothesized that a link may exist between these two hormones. As expected, the FGF21-adiponectin axis has been demonstrated. It has been demonstrated in humans that FGF21 analogue LY2405319 increases adiponectin in a dose-dependent manner (41), and FGF21 stimulates both total and HMW
A
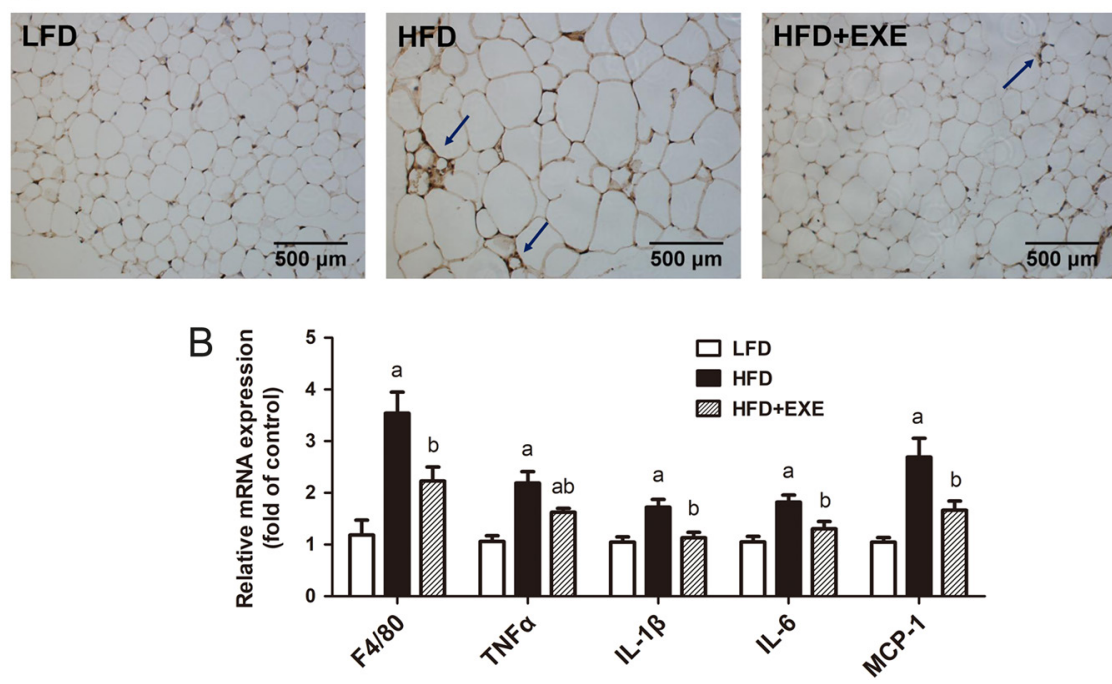

Figure 5

Exercise inhibits inflammation in epididymal WAT. (A) Immunohistochemical staining with an anti-mouse F4/80 antibody of WAT. Images were observed using a $20 \times$ objective. The arrows point to the crown-like structures formed by macrophage aggregation. (B) mRNA expression of inflammation-related genes in WAT. Data are presented as the mean \pm S.E.M.; $n=9$ per group. a $P<0.05$ for difference from LFD; ${ }^{b} p<0.05$ for difference from HFD.

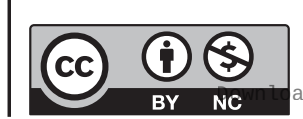

This work is licensed under a Creative Commons Attribution-NonCommercial 4.0 International License. ded from Bioscientifica.com at 04/26/2023 07:21:16AM via free access 
adiponectin secretion (12). Adiponectin acts as a mediator of the beneficial metabolic effects of FGF21 (11). The FGF21-adiponectin axis participates in the regulation of diverse biological processes, including glucose and lipid metabolism. It is worthwhile to note that disturbed FGF21-adiponectin function is observed in chronic metabolic disease such as obesity and diabetes, suggested by elevated FGF21 levels and reduced adiponectin levels (13) and is further demonstrated by our current study showing that the ability of FGF21 to induce total and HWM adiponectin was impaired in diet-induced obese mice. Amelioration of the FGF21-adiponectin axis dysfunction may be a promising target for the prevention and treatment of obesity and T2DM.

Exercise alleviates insulin resistance and improves glucose homeostasis. These effects are primarily attributed to adaptations in skeletal muscle (27). However growing evidence shows that besides skeletal muscle, many other tissues such as liver and adipose tissue are involved in exercise-induced benefits in glucose homeostasis $(42,43)$. The FGF21-adiponectin axis facilitates liver-toadipose tissue communication and plays a crucial role in glucose and lipid metabolism regulation. To explore the effects of exercise training on the FGF21-adiponecin axis, we started with analysis of FGF21 and adiponectin levels. Exercise did not alter serum FGF21 levels but significantly elevated circulating concentrations of total and HWM adiponectin, and led to a marked increase in adiponectin mRNA levels. A recent study found exerciseelicited adiponectin elevation was mediated by FGF21 (44). We conclude that the increase adiponectin levels observed in our study may due to the enhancement of endogenous FGF21 function to induce adiponectin. It was reported that a single bolus of exogenous FGF21 could stimulate adiponectin secretion (11). We further examined the ability of exogenous FGF21 to induce adiponectin. Our current study showed that exercise significantly alleviated the HFD-induced impairment of FGF21 to stimulate total adiponectin. More impressively, HFD-elicited impaired ability of FGF21 to induce HWM adiponectin, the most biologically active adiponectin isoform, was completely restored by exercise training. Our current data indicated that exercise enhanced the levels of FGF21-induced adiponectin, particularly the HMW isoform in HFD-induced obese mice. The molecular mechanisms for FGF21-elicited adiponectin secretion remain imperfectly understood. PPAR $\gamma$ has been suggested to play an important role in FGF21-induced adiponectin (11). Further work is needed to investigate whether PPAR $\gamma$ takes part in the exercise-elicited enhanced function of FGF21 to induce adiponectin.

FGF21 levels are increased significantly in humans and animals with obesity or diabetes (45), while the physiologic action of FGF21 such as glucose-lowering and nonestesterified fatty acid (NEFA)-lowing effect is attenuated, indicating reduced FGF21 sensitivity (46). Decreased expression of FGF21 co-receptor $\beta$-klotho and FGFRs may contribute to the impaired FGF21 sensitivity in obesity (46). In the present study we found that $\beta$-klotho as well as FGFR1 and FGFR2 were upregulated by exercise in diet-induced obese mice. However, serum levels of FGF21 were not significantly changed by exercise training. These results imply that the exercise-induced improvement in the FGF21-adiponectin axis may be through the upregulation of FGF21 sensitivity, rather than FGF21 expression itself.

The precise molecular mechanism responsible for the FGF21-adiponectin axis dysfunction is not clearly determined. The impaired FGF21-adiponectin axis is a manifestation of adipose tissue dysfunction, which is considered to be related to inflammation (47). Proinflammatory cytokines such as TNF $\alpha$ and IL-1 $\beta$ inhibit $\beta$-klotho expression and impair FGF21 action $(21,22)$. In the present study, we found that exercise training ameliorated the FGF21-adiponectin axis impairment, with concomitant inhibition of inflammation in adipose tissue. However, whether exercise alleviates the FGF21adiponectin axis dysfunction through the reduction of inflammation in adipose tissue needs further research.

In summary, our current data demonstrate that exercise training inhibits adipose tissue inflammation and leads to liver-to-adipose tissue communication via improving the FGF21-adiponecitin axis impairment, which seems to be plausible mechanism for exerciserelated benefits in glucose homeostasis and insulin resistance. A recent study by Leiluo Geng et al. also identified that exercise increased $\beta$-klotho and FGFR1 in adipose tissue and protected against HFD-induced FGF21 resistance (44). More impressively, they found that adipose $\beta$-klotho-deficient mice were resistant to exercisemediated metabolic benefits and showed lower levels of exercise-induced adiponectin, further indicating that the FGF21-adiponectin axis serves as a crucial mediator of exercise-induced metabolic improvement.

\section{Supplementary data}

This is linked to the online version of the paper at https://doi.org/10.1530/ EC-19-0034.
This work is licensed under a Creative Commons Attribution-NonCommercial 4.0 International License. ded from Bioscientifica.com at 04/26/2023 07:21:16AM 


\section{Declaration of interest}

The authors declare that there is no conflict of interest that could be perceived as prejudicing the impartiality of the research reported.

\section{Funding}

This work was supported by grants from the National Natural Science foundation of China (31801006) and the Young talent with the spirit of innovation foundation of Guangdong Province (518008060237).

\section{Author contribution statement}

Liangming Li designed the research; Wenqi Yang, Ling Liu, Jinbao Chen, Qinghua Han, Meifang Huang, Xuan Tan, Qiuyue Liu, Qiang Pan, Lu Zhang and Xiaojuan Lei performed the research; Yuan Wei, Chunlu Fang, Fu Zhou analyzed data; Liangming Li and Wenqi Yang wrote the paper.

\section{References}

1 Ogurtsova K, da Rocha Fernandes JD, Huang Y, Linnenkamp U, Guariguata L, Cho NH, Cavan D, Shaw JE \& Makaroff LE. IDF Diabetes Atlas: global estimates for the prevalence of diabetes for 2015 and 2040. Diabetes Research and Clinical Practice 2017128 40-50. (https://doi.org/10.1016/j.diabres.2017.03.024)

2 Shaw JE, Sicree RA \& Zimmet PZ. Global estimates of the prevalence of diabetes for 2010 and 2030. Diabetes Research and Clinical Practice 201087 4-14. (https://doi.org/10.1016/j.diabres.2009.10.007)

3 Camporez JP, Asrih M, Zhang D, Kahn M, Samuel VT, Jurczak MJ $\&$ Jornayvaz FR. Hepatic insulin resistance and increased hepatic glucose production in mice lacking FGF21. Journal of Endocrinology 2015226 207-217. (https://doi.org/10.1530/JOE-15-0136)

4 Badman MK, Pissios P, Kennedy AR, Koukos G, Flier JS \& MaratosFlier E. Hepatic fibroblast growth factor 21 is regulated by PPARalpha and is a key mediator of hepatic lipid metabolism in ketotic states. Cell Metabolism 20075 426-437. (https://doi.org/10.1016/j. cmet.2007.05.002)

5 Li H, Wu G, Fang Q, Zhang M, Hui X, Sheng B, Wu L, Bao Y, $\mathrm{Li}$ P, Xu A, et al. Fibroblast growth factor 21 increases insulin sensitivity through specific expansion of subcutaneous fat. Nature Communications 20189 272. (https://doi.org/10.1038/s41467-01702677-9)

6 Kharitonenkov A, Shiyanova TL, Koester A, Ford AM, Micanovic R, Galbreath EJ, Sandusky GE, Hammond LJ, Moyers JS, Owens RA, et al. FGF-21 as a novel metabolic regulator. Journal of Clinical Investigation 2005115 1627-1635. (https://doi.org/10.1172/JCI23606)

7 Suzuki M, Uehara Y, Motomura-Matsuzaka K, Oki J, Koyama Y, Kimura M, Asada M, Komi-Kuramochi A, Oka S \& Imamura T. betaKlotho is required for fibroblast growth factor (FGF) 21 signaling through FGF receptor (FGFR) 1c and FGFR3c. Molecular Endocrinology 200822 1006-1014. (https://doi.org/10.1210/me.2007-0313)

8 Markan KR, Naber MC, Ameka MK, Anderegg MD, Mangelsdorf DJ, Kliewer SA, Mohammadi M \& Potthoff MJ. Circulating FGF21 is liver derived and enhances glucose uptake during refeeding and overfeeding. Diabetes 201463 4057-4063. (https://doi.org/10.2337/ db14-0595)

9 Foltz IN, Hu S, King C, Wu X, Yang C, Wang W, Weiszmann J, Stevens J, Chen JS, Nuanmanee N, et al. Treating diabetes and obesity with an FGF21-mimetic antibody activating the betaKlotho/FGFR1c receptor complex. Science Translational Medicine 20124 162ra153. (https://doi.org/10.1126/scitranslmed.3004690)

10 Ding X, Boney-Montoya J, Owen BM, Bookout AL, Coate KC, Mangelsdorf DJ \& Kliewer SA. betaKlotho is required for fibroblast growth factor 21 effects on growth and metabolism. Cell Metabolism 201216 387-393. (https://doi.org/10.1016/j.cmet.2012.08.002)

11 Lin Z, Tian H, Lam KS, Lin S, Hoo RC, Konishi M, Itoh N, Wang Y, Bornstein SR, Xu A, et al. Adiponectin mediates the metabolic effects of FGF21 on glucose homeostasis and insulin sensitivity in mice. Cell Metabolism 201317 779-789. (https://doi.org/10.1016/j. cmet.2013.04.005)

12 Holland WL, Adams AC, Brozinick JT, Bui HH, Miyauchi Y, Kusminski CM, Bauer SM, Wade M, Singhal E, Cheng CC, et al. An FGF21-adiponectin-ceramide axis controls energy expenditure and insulin action in mice. Cell Metabolism 201317 790-797. (https:// doi.org/10.1016/j.cmet.2013.03.019)

13 Hui X, Feng T, Liu Q, Gao Y \& Xu A. The FGF21-adiponectin axis in controlling energy and vascular homeostasis. Journal of Molecular Cell Biology 20168 110-119. (https://doi.org/10.1093/jmcb/mjw013)

14 Park DR, Park KH, Kim BJ, Yoon CS \& Kim UH. Exercise ameliorates insulin resistance via $\mathrm{Ca} 2+$ signals distinct from those of insulin for GLUT4 translocation in skeletal muscles. Diabetes $2015 \mathbf{6 4}$ 1224-1234. (https://doi.org/10.2337/db14-0939)

15 Kolahdouzi S, Talebi-Garakani E, Hamidian G \& Safarzade A. Exercise training prevents high-fat diet-induced adipose tissue remodeling by promoting capillary density and macrophage polarization. Life Sciences 2019220 32-43. (https://doi.org/10.1016/j.lfs.2019.01.037)

16 Kriketos AD, Gan SK, Poynten AM, Furler SM, Chisholm DJ \& Campbell LV. Exercise increases adiponectin levels and insulin sensitivity in humans. Diabetes Care 200427 629-630. (https://doi. org/10.2337/diacare.27.2.629)

17 Tanimura Y, Aoi W, Takanami Y, Kawai Y, Mizushima K, Naito Y \& Yoshikawa T. Acute exercise increases fibroblast growth factor 21 in metabolic organs and circulation. Physiological Reports 20164 e12828. (https://doi.org/10.14814/phy2.12828)

18 Hansen JS, Pedersen BK, Xu G, Lehmann R, Weigert C \& Plomgaard P. Exercise-induced secretion of FGF21 and follistatin are blocked by pancreatic clamp and impaired in Type 2 diabetes. Journal of Clinical Endocrinology and Metabolism $20161012816-2825$. (https://doi.org/10.1210/jc.2016-1681)

19 Fernando P, Bonen A \& Hoffman-Goetz L. Predicting submaximal oxygen consumption during treadmill running in mice. Canadian Journal of Physiology and Pharmacology 199371 854-857. (https://doi. org/10.1139/y93-128)

20 Konrad D, Rudich A \& Schoenle EJ. Improved glucose tolerance in mice receiving intraperitoneal transplantation of normal fat tissue. Diabetologia 200750 833-839. (https://doi.org/10.1007/s00125-0070596-1)

21 Diaz-Delfin J, Hondares E, Iglesias R, Giralt M, Caelles C \& Villarroya F. TNF-alpha represses beta-klotho expression and impairs FGF21 action in adipose cells: involvement of JNK1 in the FGF21 pathway. Endocrinology 2012153 4238-4245. (https://doi. org/10.1210/en.2012-1193)

22 Zhao Y, Meng C, Wang Y, Huang H, Liu W, Zhang JF, Zhao H, Feng B, Leung PS \& Xia Y. IL-1beta inhibits beta-klotho expression and FGF19 signaling in hepatocytes. American Journal of Physiology: Endocrinology and Metabolism 2016310 E289-E300. (https://doi. org/10.1152/ajpendo.00356.2015)

23 Romeo GR, Pae M, Eberle D, Lee J \& Shoelson SE. Profilin-1 haploinsufficiency protects against obesity-associated glucose intolerance and preserves adipose tissue immune homeostasis. Diabetes 201362 3718-3726. (https://doi.org/10.2337/db13-0050)

$24 \mathrm{Mul}$ JD, Stanford KI, Hirshman MF \& Goodyear LJ. Exercise and regulation of carbohydrate metabolism. Progress in Molecular Biology and Translational Science 2015135 17-37. (https://doi.org/10.1016/ bs.pmbts.2015.07.020)

25 Yanai H, Adachi H, Masui Y, Katsuyama H, Kawaguchi A, Hakoshima M, Waragai Y, Harigae T, Hamasaki H \& Sako A. Exercise therapy for patients with type 2 diabetes: a narrative review.
This work is licensed under a Creative Commons Attribution-NonCommercial 4.0 International License. ded from Bioscientifica.com at 04/26/2023 07:21:16AM 
Journal of Clinical Medicine Research 201810 365-369. (https://doi. org/10.14740/jocmr3382w)

26 Slentz CA, Tanner CJ, Bateman LA, Durheim MT, Huffman KM, Houmard JA \& Kraus WE. Effects of exercise training intensity on pancreatic beta-cell function. Diabetes Care 200932 1807-1811. (https://doi.org/10.2337/dc09-0032)

27 Prior SJ, Blumenthal JB, Katzel LI, Goldberg AP \& Ryan AS. Increased skeletal muscle capillarization after aerobic exercise training and weight loss improves insulin sensitivity in adults with IGT. Diabetes Care 201437 1469-1475. (https://doi.org/10.2337/dc13-2358)

28 Nishimura T, Nakatake Y, Konishi M \& Itoh N. Identification of a novel FGF, FGF-21, preferentially expressed in the liver. Biochimica et Biophysica Acta 20001492 203-206. (https://doi.org/10.1016/S01674781(00)00067-1)

29 Gong Q, Hu Z, Zhang F, Cui A, Chen X, Jiang H, Gao J, Chen X, Han Y, Liang $Q$, et al. Fibroblast growth factor 21 improves hepatic insulin sensitivity by inhibiting mammalian target of rapamycin complex 1 in mice. Hepatology 201664 425-438. (https://doi. org/10.1002/hep.28523)

30 So WY, Cheng Q, Xu A, Lam KS \& Leung PS. Loss of fibroblast growth factor 21 action induces insulin resistance, pancreatic islet hyperplasia and dysfunction in mice. Cell Death and Disease 20156 e1707. (https://doi.org/10.1038/cddis.2015.80)

31 Kim KH, Kim SH, Min YK, Yang HM, Lee JB \& Lee MS. Acute exercise induces FGF21 expression in mice and in healthy humans. PLoS ONE 20138 e63517. (https://doi.org/10.1371/journal.pone.0063517)

32 Hansen JS, Clemmesen JO, Secher NH, Hoene M, Drescher A, Weigert C, Pedersen BK \& Plomgaard P. Glucagon-to-insulin ratio is pivotal for splanchnic regulation of FGF-21 in humans. Molecular Metabolism 20154 551-560. (https://doi.org/10.1016/j. molmet.2015.06.001)

33 Yang SJ, Hong HC, Choi HY, Yoo HJ, Cho GJ, Hwang TG, Baik SH, Choi DS, Kim SM \& Choi KM. Effects of a three-month combined exercise programme on fibroblast growth factor 21 and fetuin-A levels and arterial stiffness in obese women. Clinical Endocrinology 201175 464-469. (https://doi.org/10.1111/j.13652265.2011.04078.x)

34 Besse-Patin A, Montastier E, Vinel C, Castan-Laurell I, Louche K, Dray C, Daviaud D, Mir L, Marques MA, Thalamas C, et al. Effect of endurance training on skeletal muscle myokine expression in obese men: identification of apelin as a novel myokine. International Journal of Obesity 201438 707-713. (https://doi.org/10.1038/ijo.2013.158)

35 Scherer PE, Williams S, Fogliano M, Baldini G \& Lodish HF. A novel serum protein similar to $\mathrm{C} 1 \mathrm{q}$, produced exclusively in adipocytes. Journal of Biological Chemistry 1995270 26746-26749. (https://doi. org/10.1074/jbc.270.45.26746)

36 Weyer C, Funahashi T, Tanaka S, Hotta K, Matsuzawa Y, Pratley RE \& Tataranni PA. Hypoadiponectinemia in obesity and type 2 diabetes: close association with insulin resistance and hyperinsulinemia. Journal of Clinical Endocrinology and Metabolism 200186 1930-1935. (https://doi.org/10.1210/jcem.86.5.7463)

37 Yamauchi T, Kamon J, Waki H, Terauchi Y, Kubota N, Hara K, Mori Y, Ide T, Murakami K, Tsuboyama-Kasaoka N, et al. The fat-derived hormone adiponectin reverses insulin resistance associated with both lipoatrophy and obesity. Nature Medicine 20017 941-946. (https:// doi.org/10.1038/90984)

38 Pajvani UB, Du X, Combs TP, Berg AH, Rajala MW, Schulthess T, Engel J, Brownlee M \& Scherer PE. Structure-function studies of the adipocyte-secreted hormone Acrp30/adiponectin. Implications fpr metabolic regulation and bioactivity. Journal of Biological Chemistry 2003278 9073-9085. (https://doi. org/10.1074/jbc.M207198200)

39 Wickham EP 3rd, Cheang KI, Clore JN, Baillargeon JP \& Nestler JE. Total and high-molecular weight adiponectin in women with the polycystic ovary syndrome. Metabolism: Clinical and Experimental 201160 366-372. (https://doi.org/10.1016/j.metabol.2010.02.019)

40 Waki H, Yamauchi T, Kamon J, Ito Y, Uchida S, Kita S, Hara K, Hada Y, Vasseur F, Froguel P, et al. Impaired multimerization of human adiponectin mutants associated with diabetes. Molecular structure and multimer formation of adiponectin. Journal of Biological Chemistry 2003278 40352-40363. (https://doi.org/10.1074/jbc. M300365200)

41 Gaich G, Chien JY, Fu H, Glass LC, Deeg MA, Holland WL, Kharitonenkov A, Bumol T, Schilske HK \& Moller DE. The effects of LY2405319, an FGF21 analog, in obese human subjects with type 2 diabetes. Cell Metabolism 201318 333-340. (https://doi. org/10.1016/j.cmet.2013.08.005)

42 Stanford KI, Middelbeek RJ, Townsend KL, Lee MY, Takahashi H, So K, Hitchcox KM, Markan KR, Hellbach K, Hirshman MF, et al. A novel role for subcutaneous adipose tissue in exercise-induced improvements in glucose homeostasis. Diabetes 201564 2002-2014. (https://doi.org/10.2337/db14-0704)

43 Marinho R, Ropelle ER, Cintra DE, De Souza CT, Da Silva AS, Bertoli FC, Colantonio E, D'Almeida V \& Pauli JR. Endurance exercise training increases APPL1 expression and improves insulin signaling in the hepatic tissue of diet-induced obese mice, independently of weight loss. Journal of Cellular Physiology 2012227 2917-2926. (https://doi.org/10.1002/jcp.23037)

44 Geng L, Liao B, Jin L, Huang Z, Triggle CR, Ding H, Zhang J, Huang Y, Lin Z \& Xu A. Exercise alleviates obesity-induced metabolic dysfunction via enhancing FGF21 sensitivity in adipose tissues. Cell Reports 201926 2738-2752.e4. (https://doi.org/10.1016/j. celrep.2019.02.014)

45 Zhang X, Yeung DC, Karpisek M, Stejskal D, Zhou ZG, Liu F, Wong RL, Chow WS, Tso AW, Lam KS, et al. Serum FGF21 levels are increased in obesity and are independently associated with the metabolic syndrome in humans. Diabetes 200857 1246-1253. (https://doi.org/10.2337/db07-1476)

46 Fisher FM, Chui PC, Antonellis PJ, Bina HA, Kharitonenkov A, Flier JS \& Maratos-Flier E. Obesity is a fibroblast growth factor 21 (FGF21)-resistant state. Diabetes 201059 2781-2789. (https://doi. org/10.2337/db10-0193)

47 Crewe C, An YA \& Scherer PE. The ominous triad of adipose tissue dysfunction: inflammation, fibrosis, and impaired angiogenesis. Journal of Clinical Investigation 2017127 74-82. (https://doi. org/10.1172/JCI88883)

Received in final form 7 April 2019

Accepted 11 April 2019

Accepted Preprint published online 11 April 2019 https://ec.bioscientifica.com https://doi.org/10.1530/EC-19-0034
(C) 2019 The authors Published by Bioscientifica Ltd

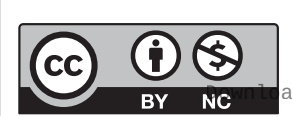

This work is licensed under a Creative Commons Attribution-NonCommercial 4.0 International License. ded from Bioscientifica.com at 04/26/2023 07:21:16AM 